\title{
miR-361-5p regulates ovarian cancer cell proliferation and apoptosis by targeting TRAF3
}

\author{
JIANMEI LING ${ }^{1}$ and PANWEN HE ${ }^{2}$ \\ ${ }^{1}$ Department of Obstetrics and Gynecology, Nantong Maternal and Child Health Care Hospital, Nantong, Jiangsu 226000; \\ ${ }^{2}$ Clinical Laboratory, The Central Hospital of Wuhan, Tongji Medical College, \\ Huazhong University of Science and Technology, Wuhan, Hubei 430010, P.R. China
}

Received May 22, 2019; Accepted January 13, 2020

DOI: $10.3892 /$ etm.2021.9632

\begin{abstract}
An increasing body of evidence has demonstrated that the abnormal expression of microRNAs (miRNAs) participate in the development and progression of ovarian cancer. miR-361-5p has been reported to serve as a tumor suppressor or oncogene in a number of different human cancer types. In the current study, it was indicated that miR-361-5p was highly expressed in ovarian cancer tissues. Compared with human ovarian epithelial cells HOSEpiC, miR-361-5p was upregulated in ovarian cancer cell lines, including in ES-2 and SKOV3 cells. The binding sites between TNF receptor-associated factor 3 (TRAF3; a member of the TRAF family of cytoplasmic adaptor proteins) and miR-361-5p were predicted using TargetScan, and a dual luciferase reporter gene assay verified the result. Subsequently, a reverse transcription-quantitative PCR assay and western blot assay indicated that TRAF3 was downregulated in ovarian cancer tissues and cell lines. It was demonstrated that miR-361-5p inhibitor significantly reduced the viability of SKOV3 cells and induced apoptosis. However, all changes were reversed by TRAF3 silencing. Furthermore, it was demonstrated that miR-361-5p inhibitor decreased the expression of p-p65 in SKOV3 cells, indicating the inhibition of the NF-kB signaling pathway. In conclusion, miR-361-5p may regulate the proliferation and apoptosis of ovarian cancer cells by targeting TRAF3. Therefore, targeting miR-361-5p may exhibit therapeutic potential in the treatment of ovarian cancer.
\end{abstract}

\section{Introduction}

Ovarian cancer is a common gynecological malignant solid tumor, and it also exhibits the highest mortality of cancer of

Correspondence to: Mr. Panwen He, Clinical Laboratory, The Central Hospital of Wuhan, Tongji Medical College, Huazhong University of Science and Technology, 26 Shengli Street, Wuhan, Hubei 430010, P.R. China

E-mail: hepw220519@163.com

Key words: microRNA-361-5p, ovarian cancer, TNF receptor-associated factor 3 the female reproductive tract (1-3). The majority of patients are diagnosed at the advanced stage. With the advancement of technology, the treatment of ovarian cancer has been significantly improved in the past few years, however, the 5-year overall survival rate for patients with ovarian cancer is still low $(4,5)$. Therefore, it is important to identify new targets for the treatment of ovarian cancer.

MicroRNAs (miRNAs) are highly conservative short non-coding RNAs that are 20-24 nucleotides in length and can post-transcriptionally regulate gene expression (6-9). miRNAs can mediate degradation or inhibit translation of mRNAs by directly binding to the 3'untranslated region (3'UTR) $(10,11)$. A growing number of studies have demonstrated that the abnormal expression and function of miRNAs serves an important role in the pathogenesis of malignant disease $(12,13)$. It has been reported that miR-205 can induce cell invasion by inhibiting transcription factor 21 in human ovarian cancer (14). Furthermore, miR-663 has been demonstrated to promote cell proliferation, migration and invasion by targeting TUSC2 in ovarian cancer (15). Cui et al (16) reported that miR-361-5p was downregulated in hepatocellular carcinoma (HCC) and suppressed HCC proliferation and invasion through targeting VEGFA. Ma et al (17) demonstrated that miR-361-5p expression was associated with prognosis in patients with breast cancer. A recent study has indicated that miR-361-5p was upregulated in serous ovarian carcinoma (18). However, another study reported that miR-361-5p was downregulated in epithelial ovarian cancer (19). Therefore, the expression and role of miR-361-5p in ovarian cancer is controversial, and further research is required.

TNF receptor-associated factor 3 (TRAF3) is a member of the TRAF family and is ubiquitously expressed in a number of tissues and cells, including in the brain, lungs, heart, spleen and liver $(20,21)$. TRAF3 is currently considered to be a central regulator of the ischemic signaling cascade, including neuronal death, neuronal apoptosis, inflammation and oxidative stress (22). Through bioinformatics software analysis, the current study identified the binding sites between miR-361-5p and TRAF3. Therefore, it was hypothesized that miR-361-5p may affect ovarian cancer cell growth through regulating the expression of TRAF3. 
The aim of the present study was to explore the role and mechanism of miR-361-5p in ovarian cancer cells.

\section{Materials and methods}

Clinical specimens collection. Human ovarian cancer tissues and adjacent normal tissues were obtained from 30 patients with ovarian cancer from Nantong Maternal and Child Health Care Hospital. These specimens were stored in liquid nitrogen or at $-80^{\circ} \mathrm{C}$ for subsequent use. The experiment was approved by the Ethics Committee of Nantong Maternal and Child Health Care Hospital. All patients were notified that their specimens would be used in the current research, and written informed consent was obtained from every patient.

Cell culture and transfection. Human ovarian cancer cell lines, SKOV3 and ES-2 were obtained from the American Type Culture Collection, and human ovarian surface epithelial cells (HOSEpiC) were purchased from the BeNa Cell Culture Collection (cat. no. BNCC340096). SKOV3 and ES-2 cells were cultured in RPMI-1640 medium (Gibco; Thermo Fisher Scientific, Inc.) supplemented with 10\% FBS (Gibco; Thermo Fisher Scientific, Inc.) at $37^{\circ} \mathrm{C}$ with $5 \% \mathrm{CO}_{2}$. HOSEpiC cells were cultured in DMEM medium (Gibco; Thermo Fisher Scientific, Inc.) containing 10\% FBS.

SKOV3 cells were transfected with inhibitor control, miR-361-5p inhibitor, TRAF3-short-hairpin (sh)RNA, control-shRNA, miR-361-5p inhibitor + control-shRNA or miR-361-5p inhibitor + TRAF3-shRNA for $48 \mathrm{~h}$ using Lipofectamine 2000 reagent (Invitrogen; Thermo Fisher Scientific, Inc.) according to the manufacturer's protocol. A period of $48 \mathrm{~h}$ after cell transfection, transfection efficiency was detected using reverse transcription-quantitative (RT-q) PCR.

$R T-q P C R$. Total RNA was acquired using TRIzol reagent (Invitrogen; Thermo Fisher Scientific, Inc.) in line with the manufacturer's protocol, and RNA was stored at $-80^{\circ} \mathrm{C}$. RNA was subsequently reverse transcribed into complementary DNA using a reverse transcription kit (Vazyme), according to the manufacturer's protocol. RT-qPCR was performed using SYBR Green PCR Master Mix (Vazyme) following the manufacturer's protocol. The reaction conditions were as follows: $95^{\circ} \mathrm{C}$ for $5 \mathrm{~min}$, followed by 35 cycles of amplification at $95^{\circ} \mathrm{C}$ for $30 \mathrm{sec}, 60^{\circ} \mathrm{C}$ for $30 \mathrm{sec}$ and $72^{\circ} \mathrm{C}$ for $30 \mathrm{sec}$. U6 or GAPDH was used for normalization. The primer sequences for qPCR were as follows: U6 forward, 5'-GCTTCGGCA GCACATATACTAAAAT-3' and reverse, 5'-CGCTTCACG AATTTGCGTGTCAT-3'; GAPDH forward, 5'-CTTTGGT ATCGTGGAAGGACTC-3' and reverse 5'-GTAGAGGCA GGGATGATGTTCT-3'; miR-361-5p forward, 5'-ATAAAG RGCRGACAGTGCAGATAGTG-3' and reverse, 5'-TCAAGT ACCCACAGTGCGGT-3'; TRAF3 forward, 5'-GGACCG CGAGATGAGGAA-3' and reverse 5'-CGGTCAGTGTGC AGCTTTAG-3'. Additionally, gene expression was quantified using the $2^{-\triangle \Delta \mathrm{Cq}}$ method. Each experiment was performed in triplicate.

Western blot analysis. Following treatment, cells were washed three times with ice-cold PBS and lysed with RIPA lysis solution (Beijing Solarbio Science \& Technology Co., Ltd.) supplemented with protease inhibitors for $30 \mathrm{~min}$. Cells were then centrifuged at $4^{\circ} \mathrm{C}$ and stored at $-20^{\circ} \mathrm{C}$. Equal amounts of protein were separated using $12 \%$ SDS-PAGE and transferred to PVDF membranes (EMD Millipore). The membranes were blocked using 5\% skim milk in PBS containing $0.1 \%$ Tween for $2 \mathrm{~h}$. Membranes were incubated with primary antibodies at $4^{\circ} \mathrm{C}$ overnight. Subsequently, the membranes were incubated with an HRP-conjugated secondary antibody at room temperature for $2 \mathrm{~h}$. The protein band was visualized using the ECL method (EMD Millipore). $\beta$-actin was used as the loading control for normalization.

The primary antibodies used were as follows: Anti-TRAF3 (Cat. no. 61095; dilution rate: 1:1,000), anti-Bcl-2 (Cat. no. 4223; dilution rate: 1:1,000), anti-Bax (Cat. no. 5023; dilution rate: 1:1,000), anti-p-p65 (Cat. no. 3033; dilution rate: 1:1,000), anti- $\beta$-actin (Cat. no. 4970; dilution rate: 1:1,000) and anti-p65 (Cat. no. 8242; dilution rate: 1:1,000), and were purchased from Cell Signaling Technology, Inc. The secondary antibody: Horseradish peroxidase-conjugated anti-rabbit Immunoglobulin G secondary antibody (Cat. no. 7074; dilution rate: 1:2,000) was also purchased from Cell Signaling Technology, Inc.

MTT assay. MTT reagent (Beijing Solarbio Science \& Technology Co., Ltd.) was used to assess cell viability. Cells were divided into five groups: Control (SKOV3 cells without any treatment); inhibitor control (SKOV3 cells were transfected with inhibitor control for $48 \mathrm{~h}$ ); inhibitor (SKOV3 cells were transfected with miR-361-5p inhibitor for $48 \mathrm{~h}$ ); inhibitor + control-shRNA (SKOV3 cells were co-transfected with miR-361-5p inhibitor and control-shRNA for $48 \mathrm{~h}$ ); inhibitor + TRAF3-shRNA (SKOV3 cells were co-transfected with miR-361-5p inhibitor and TRAF3-shRNA for $48 \mathrm{~h}$ ). SKOV3 cells were seeded into 96-well plates at a density of 2,000 cells/well and cultured for $48 \mathrm{~h}$. Then, $20 \mu \mathrm{l}$ MTT reagent was added into each well for an additional incubation for $4 \mathrm{~h}$ at $37^{\circ} \mathrm{C}$, and $150 \mu \mathrm{l}$ DMSO was added into each well and plates were shaken for $15 \mathrm{~min}$. The optical density (OD) values were read at $490 \mathrm{~nm}$ using a micro-plate reader. Cell viability $(\%)=(\mathrm{OD}$ value of experimental group-OD value of the blank group $) /(\mathrm{OD}$ value of control group-OD value of the blank group) x100\%.

Flow cytometry assay. Cell apoptosis was analyzed using an Annexin-V/propidium iodide (PI) Apoptosis Detection kit. SKOV3 cells were plated in six-well plates at a density of $10^{6}$ cells per well overnight. The next day, cells were transfected with inhibitor control, miR-361-5p inhibitor, miR-361-5p inhibitor + control-shRNA, or miR-361-5p inhibitor + TRAF3-shRNA. Following transfection for $48 \mathrm{~h}$, the cells were collected, centrifuged at a low temperature and high speed, and re-suspended in $100 \mu 1$ of FITC-binding buffer. Subsequently, the buffer was added with $\sim 5 \mu 1$ ready-to-use Annexin V-FITC (BD Bioscience) and $5 \mu \mathrm{l}$ PI. In the dark, cells were incubated for $30 \mathrm{~min}$ at room temperature. Annexin V-FITC and PI fluorescence were assessed using a BD FACSCalibur flow cytometer (BD Biosciences). The data was subsequently analyzed using FlowJo software (version 7.2.4; FlowJo LLC). 

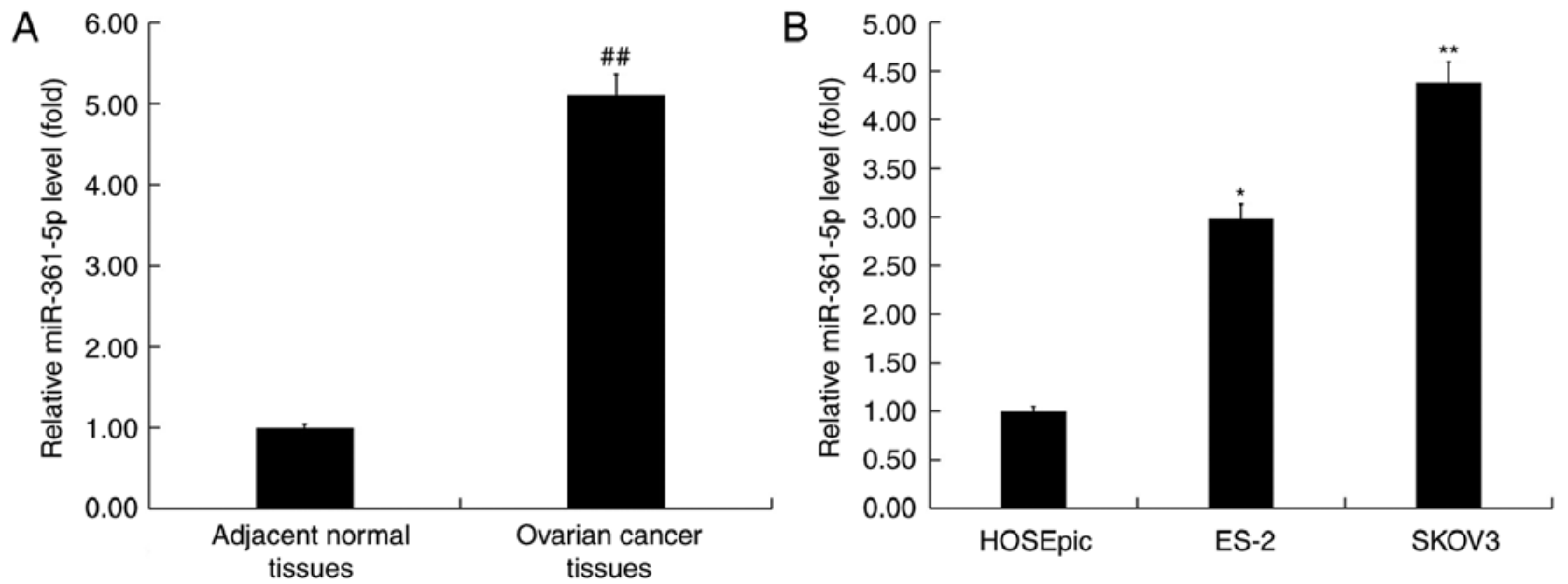

Figure 1. miR-361-5p was u-regulated in ovarian cancer tissues and cell lines. (A) RT-qPCR assay was performed to detect the expression of miR-361-5p in ovarian cancer tissues and adjacent normal tissues. (B) RT-qPCR assay was performed to detect the expression of miR-361-5p in ovarian cancer ES-2 and SKOV3 cell lines and human ovarian epithelial cells HOSEpiC. ${ }^{\# \#} \mathrm{P}<0.01$ vs. adjacent normal tissues; ${ }^{*} \mathrm{P}<0.05,{ }^{* * *} \mathrm{P}<0.01$ vs. HOSEpiC. miR, microRNA; RT-q, reverse transcription-quantitative.

Dual-luciferase reporter assay. The binding sites between TRAF3 and miR-361-5p were predicted using TargetScan (http://www.targetscan.org/vert_72/). To confirm the binding sites, a dual-luciferase reporter assay was performed. Luciferase reporter plasmids (psi-CHECK2) containing the wild-type 3'UTRs of TRAF3 and mutant 3'UTRs of TRAF3 were manufactured by TSINGKE BioTech. SKOV3 cells were co-transfected with the wild-type (WT) or mutant (MUT) 3'UTR luciferase reporter plasmids, and the miR-361-5p mimic or mimic control, res pectively, using Lipofectamine 2000 (Invitrogen; Thermo Fisher Scientific, Inc.). Cells were harvested after transfection for $48 \mathrm{~h}$, and the luciferase activities were measured using the dual-luciferase assay system (Promega Corporation) following the manufacturer's protocol. Firefly luciferase was used as the normalization control.

Statistical analysis. GraphPad Prism was used for statistical analysis. The data were presented as mean \pm standard deviation from three independent experiments in triplicate. Differences between two groups were determined using a paired Student's t-test, and comparisons between multiple groups were performed using a one-way ANOVA followed by a Tukey's test. $\mathrm{P}<0.05$ was considered to indicate a statistically significant difference.

\section{Results}

Expression of miR-361-5p in ovarian cancer tissues and cells. To explore the role of miR-361-5p in ovarian cancer, the expression of miR-361-5p was determined in ovarian cancer tissues and cancer cells using RT-qPCR. The RT-qPCR assay indicated that miR-361-5p was highly expressed in ovarian cancer tissues (Fig. 1A). The level of miR-361-5p was detected in a human ovarian clear cell carcinoma cell line ES-2 and a human ovarian adenocarcinoma cell line SKOV3. The results also demonstrated that compared with human ovarian epithelial cells HOSEpiC, miR-361-5p expression was upregulated in ES-2 and SKOV3 cells, and miR-361-5p expression was indicated to be most prominent in SKOV3 cells (Fig. 1B). SKOV3 cells were subsequently selected for further study.

TRAF3 was indicated to be a direct target of miR-361-5p. TargetScan was performed to analyze the potential target genes of miR-361-5p, and the predicted sequence analysis data indicated that TRAF3 was the target of miR-361-5p (Fig. 2A). To further verify this prediction, a dual luciferase reporter gene assay was performed, and the results demonstrated that miR-361-5p mimic significantly inhibited the luciferase activity of cells co-transfected with TRAF3-WT and miR-361-5p mimic. However, miR-361-5p mimic could not inhibit the luciferase activity of cells co-transfected with TRAF3-MUT and miR-361-5p mimic (Fig. 2B). These results indicated that TRAF3 was a direct target of miR-361-5p.

To determine the role of TRAF3 in ovarian cancer, a RT-qPCR assay was performed to detect TRAF3 mRNA expression in ovarian cancer tissues and adjacent normal tissues. A RT-qPCR assay indicated that TRAF3 was significantly downregulated in ovarian cancer tissues (Fig. 2C). Compared with HOSEpiC cells, TRAF3 expression was downregulated in ovarian cancer ES-2 and SKOV3 cells and TRAF3 expression was minimal in SKOV3 cells (Fig. 2D and E).

miR-361-5p negatively regulated TRAF3 expression in SKOV3 cells. SKOV3 cells were transfected with an inhibitor control, miR-361-5p inhibitor, TRAF3-shRNA, control-shRNA, miR-361-5p inhibitor + control-shRNA, or miR-361-5p inhibitor + TRAF3-for $48 \mathrm{~h}$. A RT-qPCR assay indicated that compared with the inhibitor control group, miR-361-5p inhibitor significantly decreased the expression of miR-361-5p in SKOV3 cells (Fig. 3A). The RT-qPCR assay and western blot analysis indicated that compared with the control-shRNA group, TRAF3-shRNA reduced the expression of TRAF3 at the mRNA and 

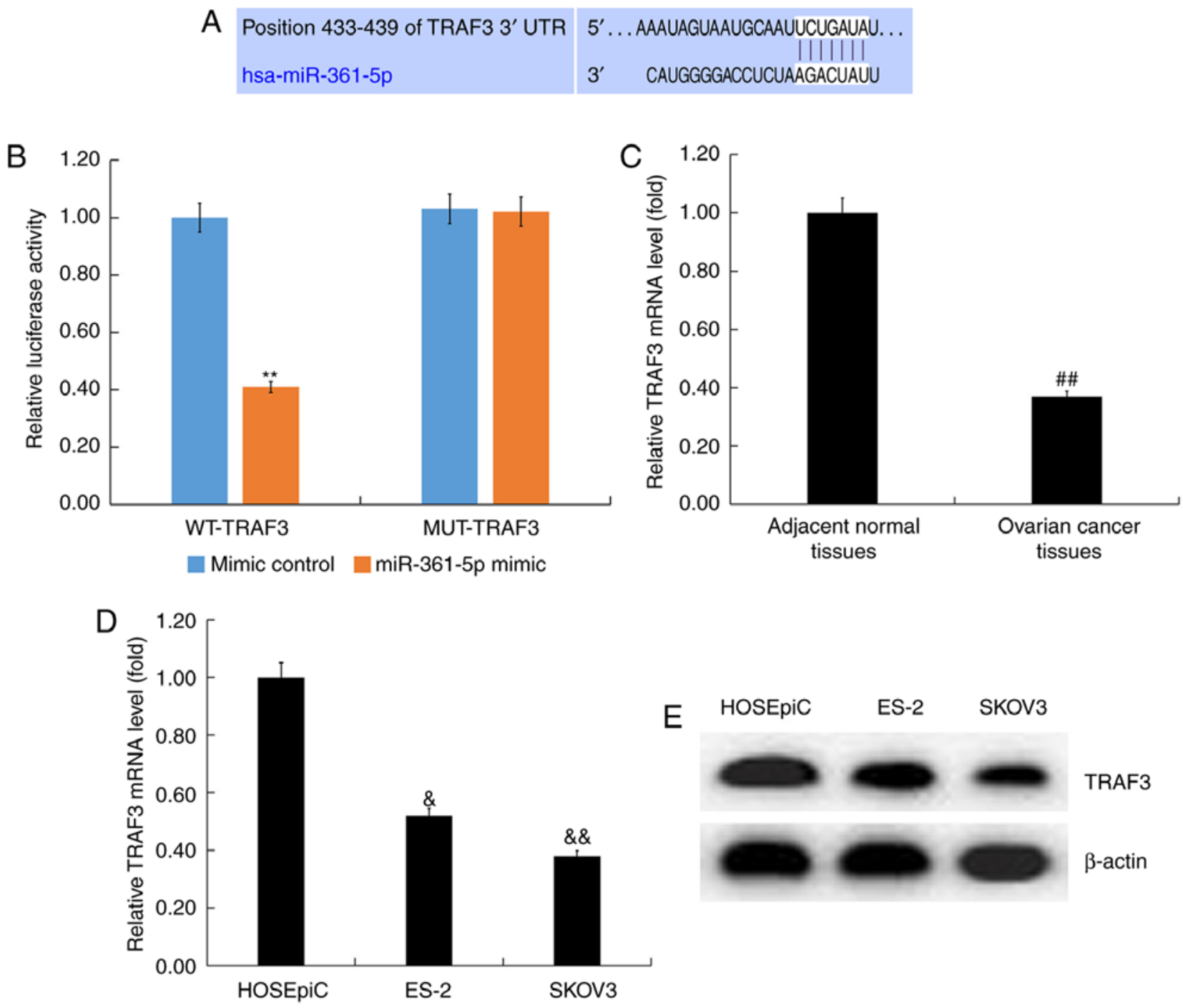

Figure 2. TRAF3 was direct target gene of miR-361-5p. (A) Interaction between miR-361-5p and 3'untranslated region of TRAF3 was predicted using microRNA target site prediction software. (B) Dual-luciferase reporter assay was performed to confirm the binding sites between HOSEpiC. (C) RT-qPCR assay detected the expression of TRAF3 at the mRNA level in ovarian cancer tissues and adjacent normal tissues. (D) RT-qPCR assay measured the mRNA expression of TRAF3 in HOSEpiC, ES-2 and SKOV3 cells. (E) Western blot analysis detected the expression of TRAF3 at protein level in HOSEpiC, ES-2 and SKOV3 cells. ${ }^{* *} \mathrm{P}<0.01$ vs. mimic control; ${ }^{\# \#} \mathrm{P}<0.01$ vs. adjacent normal tissues; ${ }^{\circledR} \mathrm{P}<0.05$, ${ }^{\& \&} \mathrm{P}<0.01$ vs. HOSEpiC. TRAF, TNF receptor-associated factor 3 ; miR, microRNA; RT-q, reverse transcription-quantitative.

protein level in SKOV3 cells (Fig. 3B and C). Additionally, compared with the inhibitor control group, miR-361-5p inhibitor promoted the expression of TRAF3 in SKOV3 cells, and this increase was reversed by TRAF3-shRNA (Fig. 3D and E).

Effect of miR-361-5p inhibitor on viability and apoptosis of SKOV3 cells. To further explore the effect of miR-361-5p inhibitor on cell viability and apoptosis of SKOV3 cells, flow cytometry and MTT assay were performed. MTT assay indicated that compared with the inhibitor control group, miR-361-5p inhibitor significantly reduced the viability of SKOV3 cells (Fig. 4A). The flow cytometry assay indicated that miR-361-5p inhibitor significantly induced SKOV3 cell apoptosis (Fig. 4B and C). Additionally, miR-361-5p inhibitor decreased $\mathrm{Bcl}-2$ expression, increased Bax expression (Fig. 4D), and decreased Bcl2/Bax ratio (Fig. 4E). All of these changes were reversed using TRAF3-shRNA. The results demonstrated that miR-361-5p inhibitor decreased SKOV3 cell viability and promoted cell apoptosis.

Effect of miR-361-5p inhibitor on NF-kB pathway in SKOV3 cells. Western blot analysis revealed the expression of p65 and p-p65 in SKOV3 cells. Compared with the inhibitor control group, miR-361-5p inhibitor markedly decreased the expression of p-p65 protein and significantly reduced p-p65/p65 ratio in SKOV3 cells, and these changes were reversed using TRAF3-shRNA (Fig. 5A and B). Therefore, the role of miR-361-5p inhibitor in ovarian cancer cells may be associated with the NF-kB signaling pathway.

\section{Discussion}

It has previously been demonstrated that miRNAs can serve as either an oncogene or tumor suppressor by directly or indirectly modulating cancer genes. In the current study, 

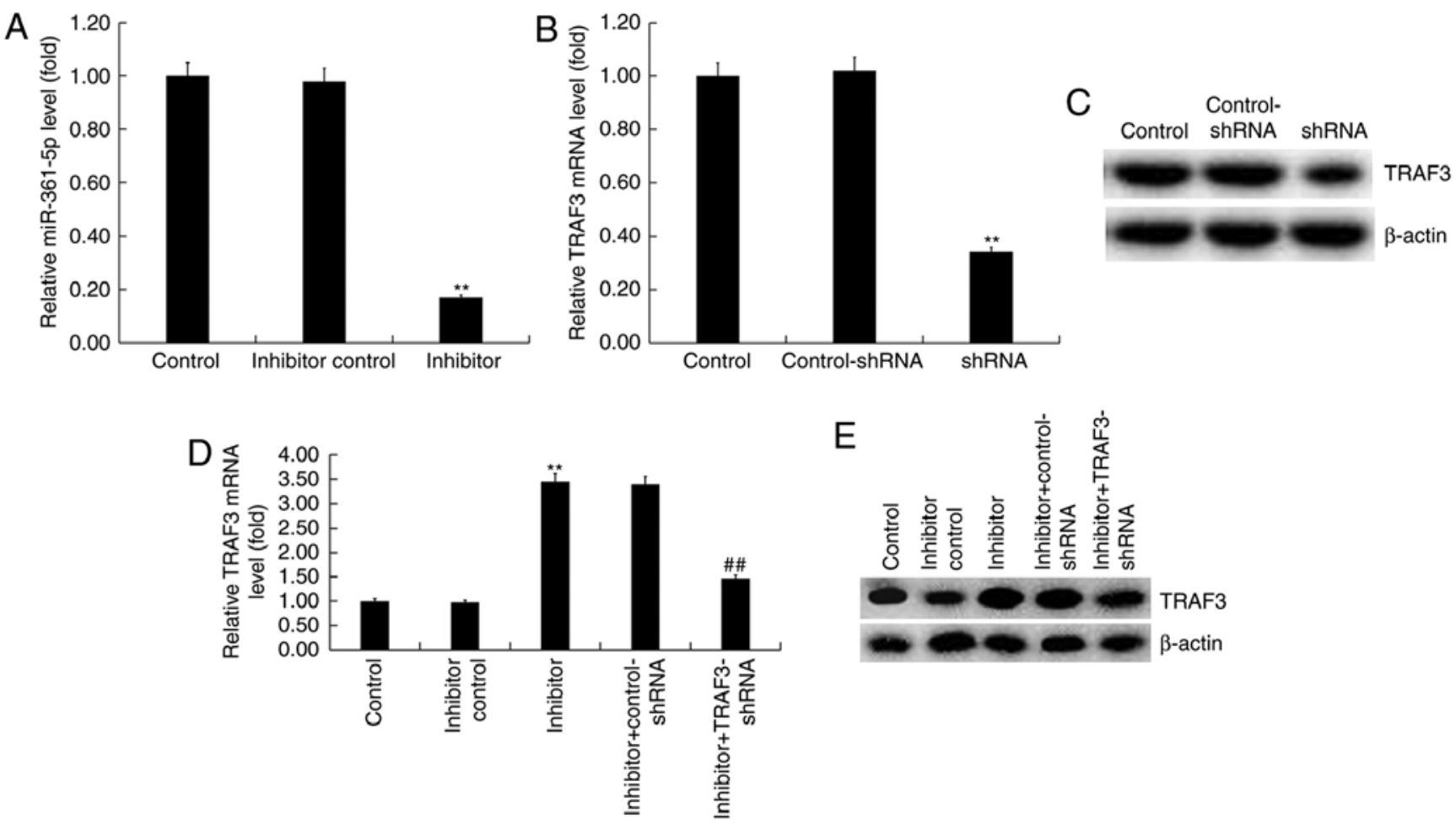

Figure 3. The expression of miR-361-5p and TRAF3 in SKOV3 cells. (A) RT-qPCR assay detected the expression of miR-361-5p in cells transfected with inhibitor control or miR-361-5p inhibitor for $48 \mathrm{~h}$. (B) RT-qPCR assay and (C) western blot analysis measured the expression of TRAF3 in cells transfected with TRAF3-shRNA or control-shRNA for $48 \mathrm{~h}$. (D) RT-qPCR assay and (E) western blot analysis detected the expression of TRAF3 in cells transfected with inhibitor control, miR-361-5p inhibitor, miR-361-5p inhibitor + control-shRNA, or miR-361-5p inhibitor + TRAF3-shRNA for 48 h. ${ }^{* *} \mathrm{P}<0.01$ vs. inhibitor control/control-shRNA; ${ }^{\# \#} \mathrm{P}<0.01$ vs. inhibitor. miR, microRNA; TRAF, TNF receptor-associated factor 3; RT-q, reverse transcription-quantitative; sh, short-hairpin.

it was revealed that miR-361-5p was highly expressed in ovarian cancer tissues and cancer cell lines. The results of TargetScan and dual luciferase reporter gene assay identified TRAF3 as a direct target of miR-361-5p. Additionally, it was demonstrated that TRAF3 was downregulated in ovarian cancer tissues and cancer cell lines. To further determine the role of miR-361-5p and TRAF3 in ovarian cancer, SK-OV-3 cells were transfected with miR-361-5p inhibitor or/and TRAF3-shRNA for $48 \mathrm{~h}$. The results indicated that miR-361-5p inhibitor significantly suppressed SK-OV-3 cell viability and induced cell apoptosis. These changes were reversed by TRAF3-shRNA.

Ovarian cancer exhibits one of the highest mortality rates of all gynecologic malignancies. Currently, the combination of surgery and chemotherapy has improved the treatment of ovarian cancer. However, the successful complete cure rate of this disease is only $30 \%$ (23). The mechanism of occurrence and development of ovarian cancer remain largely undetermined, and consequently, the identification of a new target is required to treat ovarian cancer. There is increasing evidence that miRNAs serve an important role in the early diagnosis, prognosis, prevention and treatment of cancer (24-26). It has been reported that miR-145 serves as a tumor suppressor and as a potential diagnostic target in ovarian cancer $(27,28)$. Salem et al (29) indicated that miR-590-3p promoted ovarian cancer development by targeting Cyclin G2 and FOXO3. Zhou et al (30) demonstrated that miR-183 was associated with the pathogenesis of OC. However, the role of miR-361-5p in ovarian cancer remains largely unknown.
A previous study indicated that miR-361-5p serves as a tumor suppressor, and was revealed to suppress breast cancer cell aerobic glycolysis and proliferation (17). Kanitz et al (31) demonstrated that miR-361-5p served a crucial role in human cutaneous squamous cell carcinoma. miR-361-5p has also been reported to inhibit prostate cancer cell proliferation by targeting STAT6 (32). Chen et al (18) indicated that miR-361-5p was upregulated in serous ovarian carcinoma. However, Ma et al (19) reported that miR-361-5p was downregulated in epithelial ovarian cancer. In the current study, it was demonstrated that miR-361-5p was upregulated in ovarian cancer tissues and cancer cell lines.

In the present study, it was indicated that TRAF3 was a direct target of miR-361-5p. It has been previously reported that TRAF3 is responsible for encoding the TRAF protein (33). Additionally, TRAF3 is an important part in the TLR and RLH pathways and exerts a key role in IRF3 activation (34). TRAF3 is also associated with a number of other pathways (35). Rehei et al (36) demonstrated that TRAF3 was a target of microRNA-214 in human osteosarcoma. In the present study, it was indicated that TRAF3 was downregulated in ovarian cancer tissues and cancer cell lines. miR-361-5p inhibitor significantly reduced the viability of SKOV3 cells and induced apoptosis. The results of the current study also demonstrated that miR-361-5p inhibitor could inhibit the NF-kB signaling pathway in ovarian cancer cells, and this result suggested that miR-361-5p may be associated with the NF-kB signaling pathway in ovarian cancer. All the effects of miR-361-5p inhibitor on SKOV3 cells were reversed by TRAF3 silencing. 


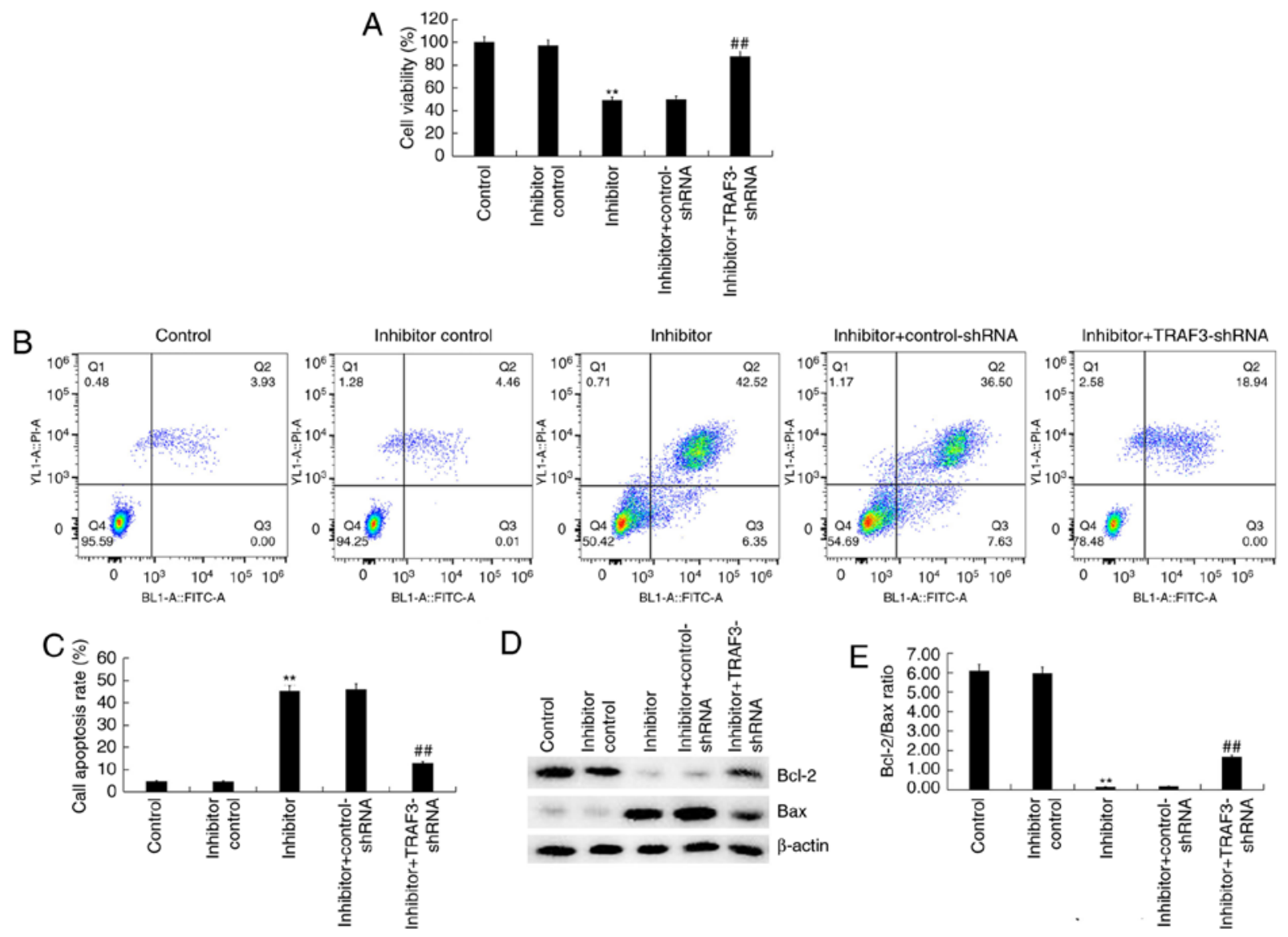

Figure 4. miR-361-5p inhibitor decreased cell viability and promoted cell apoptosis in SKOV3 cells. SKOV3 cells were transfected with inhibitor control, miR-361-5p inhibitor, miR-361-5p inhibitor + control-shRNA, or miR-361-5p inhibitor + TRAF3-shRNA for 48 h. (A) MTT assay was used to detect cell viability. (B and C) Flow cytometry assay was used to detect cell apoptosis. (D) Western blot analysis detected the protein expression of Bcl-2 and Bax. (E) The ratio of Bcl2/Bax was calculated and presented. ${ }^{* *} \mathrm{P}<0.01$ vs. inhibitor control; ${ }^{\# /} \mathrm{P}<0.01$ vs. inhibitor. miR, microRNA; sh, short-hairpin; TRAF, TNF receptor-associated factor 3 .

A

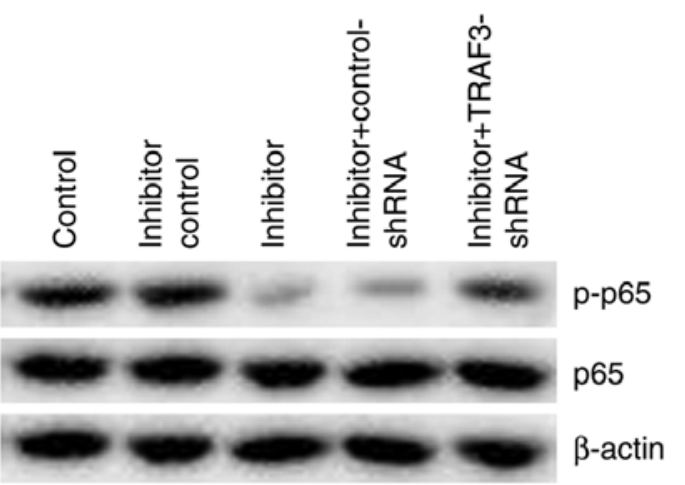

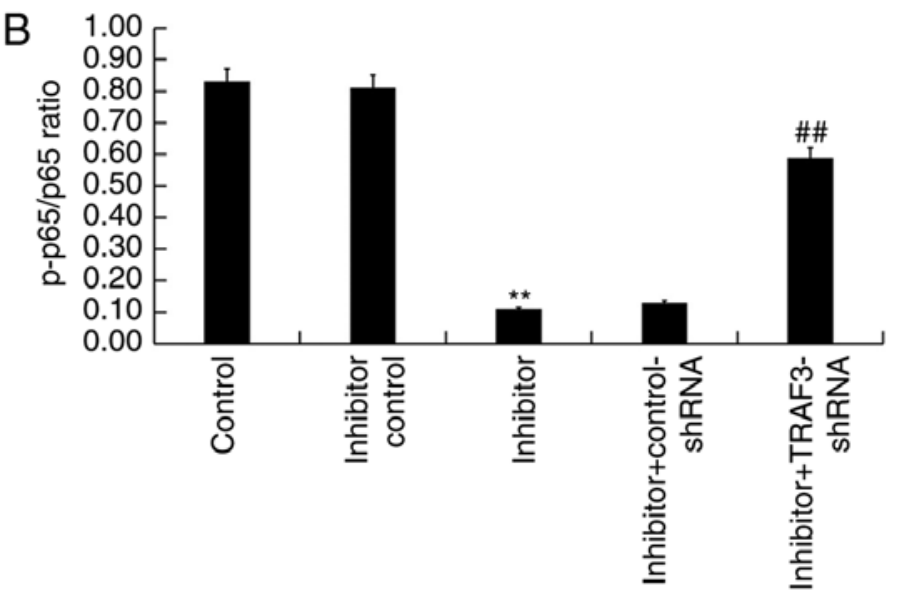

Figure 5. miR-361-5p inhibitor suppressed the expression of p-p65 in SKOV3 cells. SKOV3 cells were transfected with inhibitor control, miR-361-5p inhibitor, miR-361-5p inhibitor + control-shRNA, or miR-361-5p inhibitor + TRAF3-shRNA for $48 \mathrm{~h}$. (A) Western blot analysis determined the protein expression of p-p65 and p65. (B) p-p65/p65 was calculated and presented. ${ }^{* *} \mathrm{P}<0.01$ vs. inhibitor control; ${ }^{\# \#} \mathrm{P}<0.01$ vs. inhibitor. miR, microRNA; p, phosphorylated; sh, short-hairpin; TRAF, TNF receptor-associated factor 3.

In conclusion, miR-361-5p regulated the proliferation and apoptosis of ovarian cancer cells by targeting TRAF3 and may be a new potential therapeutic target for ovarian cancer. The current study is a preliminary study of the role of miR-361-5p in ovarian cancer. To clarify the role of miR-361-5p in ovarian cancer, the role of miR-361-5p in 
other ovarian cancer cell lines required determination. The effect of miR-361-5p/TRAF3 on ovarian cancer also required investigation in vivo. Furthermore, the relationship between the expression of miR-361-5p/TRAF3 in patients with ovarian cancer and the clinical pathological features of the patients requires investigation in future studies.

\section{Acknowledgements}

Not applicable.

\section{Funding}

No funding was received.

\section{Availability of data and materials}

The datasets used and/or analyzed during the current study are available from the corresponding author on reasonable request.

\section{Authors' contributions}

JL contributed to data collection, statistical analysis, data interpretation and manuscript preparation. $\mathrm{PH}$ contributed to data collection and data interpretation. All authors read and approved the final manuscript.

\section{Ethics approval and consent to participate}

The experiment was approved by the Ethics Committee of Nantong Maternal and Child Health Care Hospital. All patients were notified that their specimens would be used in the current research, and written informed consent was obtained from every patient.

\section{Patient consent for publication}

All patients consented to the publication of the data in this manuscript.

\section{Competing interests}

The authors declare that they have no competing interests.

\section{References}

1. Coleman RL, Monk BJ, Sood AK and Herzog TJ: Latest research and treatment of advanced-stage epithelial ovarian cancer. Nat Rev Clin Oncol 10: 211-224, 2013.

2. Bearfoot JL, Choong DY, Gorringe KL and Campbell IG: Genetic analysis of cancer-implicated MicroRNA in ovarian cancer. Clin Cancer Res 14: 7246-7250, 2008.

3. Dahiya N, Sherman-Baust CA, Wang TL, Davidson B, Shih IeM, Zhang Y, Wood W III, Becker KG and Morin PJ: MicroRNA expression and identification of putative miRNA targets in ovarian cancer. PLoS One 3: e2436, 2008.

4. Guo LM, Pu Y, Han Z, Liu T, Li YX, Liu M, Li X and Tang H: MicroRNA-9 inhibits ovarian cancer cell growth through regulation of NF-kappaB1. FEBS J 276: 5537-5546, 2009.

5. Lu L, Schwartz P, Scarampi L, Rutherford T, Canuto EM, Yu H and Katsaros D: MicroRNA let-7a: A potential marker for selection of paclitaxel in ovarian cancer management. Gynecol Oncol 122: 366-371, 2011.
6. Poy MN, Eliasson L, Krutzfeldt J, Kuwajima S, Ma X Macdonald PE, Pfeffer S, Tuschl T, Rajewsky N, Rorsman P and Stoffel M: A pancreatic islet-specifc microRNA regulates insulin secretion. Nature 432: 226-230, 2004.

7. Wang Q, Liu N, Yang X, Tu L and Zhang X: Small RNA-mediated responses to low- and high-temperature stresses in cotton. Sci Rep 6: 35558-35571, 2016.

8. Lim LP, Lau NC, Garrett-Engele P, Grimson A, Schelter JM, Castle J, Bartel DP, Linsley PS and Johnson JM: Microarray analysis shows that some microRNAs downregulate large numbers of target mRNAs. Nature 433: 769-773, 2005.

9. Bartel DP: MicroRNAs: Genomics, biogenesis, mechanism, and function. Cell 116: 281-297, 2004.

10. Wang Y, Chen F, Zhao M, Yang Z, Zhang S, Ye L, Gao H and Zhang X: MiR-107 suppresses proliferation of hepatoma cells through targeting HMGA2 mRNA 3'UTR. Biochem Biophys Res Commun 480: 455-460, 2016.

11. Zhu Q, Gong L, Wang J, Tu Q, Yao L, Zhang JR, Han XJ, Zhu SJ, Wang SM, Li YH and Zhang W: miR-10b exerts oncogenic activity in human hepatocellular carcinoma cells by targeting expression of CUB and sushi multiple domains 1 (CSMD1). BMC Cancer 16: 806, 2016.

12. Calin GA and Croce CM: MicroRNA signatures in human cancers. Nat Rev Cancer 6: 857-866, 2006.

13. Lu J, Getz G, Miska EA, Alvarez-Saavedra E, Lamb J, Peck D, Sweet-Cordero A, Ebert BL, Mak RH, Ferrando AA, et al: MicroRNA expression profiles classify human cancers. Nature 435: 834-838, 2005.

14. Wei J, Zhang L, Li J, Zhu S, Tai M, Mason CW, Chapman JA, Reynolds EA, Weiner CP and Zhou HH: MicroRNA-205 promotes cell invasion by repressing TCF21 in human ovarian cancer. J Ovarian Res 10: 33, 2017.

15. Xie HH, Huan WT, Han JQ, Ren WR and Yang LH: MicroRNA-663 facilitates the growth, migration and invasion of ovarian cancer cell by inhibiting TUSC2. Biol Res 52: 18-27, 2019.

16. Cui W, Li Y, Xu K, Chen G, Lu X, Duan Q and Kang Z: miR-361-5p inhibits hepatocellular carcinoma cell proliferation and invasion by targeting VEGFA. Biochem Biophys Res Commun 479: 901-906, 2016

17. Ma F, Zhang L, Ma L, Zhang Y, Zhang J and Guo B: MiR-361-5p inhibits glycolytic metabolism, proliferation and invasion of breast cancer by targeting FGFR1 and MMP-1. J Exp Clin Cancer Res 36: 158, 2017.

18. Chen SF, Liu Z, Chaurasiya S, Dellinger TH, Lu J, Wu X, Qin H, Wang J, Fong Y and Yuan YC: Identification of core aberrantly expressed microRNAs in serous ovarian carcinoma. Oncotarget 9: 20451-20466, 2018.

19. Ma J, Jing XT, Chen Z, Duan Z and Zhang Y: MiR-361-5p decreases the tumorigenicity of epithelial ovarian cancer cells by targeting at RPL22L1 and c-Met signaling. Int J Clin Exp Pathol 11: 2588-2596, 2018.

20. Häcker H, Tseng PH and Karin M: Expanding TRAF function: TRAF3 as a tri-faced immune regulator. Nat Rev Immunol 11: 457-468, 2011.

21. Yi Z, Lin WW, Stunz LL and Bishop GA: Roles for TNF-receptor associated factor 3 (TRAF3) in lymphocyte functions. Cytokine Growth Factor Rev 25: 147-156, 2014.

22. Gong J, Li ZZ, Guo S, Zhang XJ, Zhang P, Zhao GN, Gao L, Zhang Y, Zheng A, Zhang XF, et al: Neuron-specifc tumor necrosis factor receptor-associated factor 3 is a central regulator of neuronal death in acute ischemic stroke. Hypertension 66: 604-616, 2015.

23. Zhu CL and Gao GS: MiR-200a overexpression in advanced ovarian carcinomas as a prognostic indicator. Asian Pac J Cancer Prev 15: 8595-8601, 2014

24. Zhu L and Fang J: The structure and clinical roles of MicroRNA in colorectal cancer. Gastroenterol Res Pract 2016: 1360348, 2016.

25. Shukla KK, Misra S, Pareek P, Mishra V, Singhal B and Sharma P: Recent scenario of microRNA as diagnostic and prognostic biomarkers of prostate cancer. Urol Oncol 35: 92-101, 2017.

26. Shah MY, Ferrajoli A, Sood AK, Lopez-Berestein G and Calin GA: microRNA therapeutics in cancer-an emerging concept. EBioMedicine 12: 34-42, 2016.

27. Zhu X, Li Y, Xie C, Yin X, Liu Y, Cao Y, Fang Y, Lin X, Xu Y, $\mathrm{Xu} \mathrm{W}$, et al: miR-145 sensitizes ovarian cancer cells to paclitaxel by targeting Sp1 and Cdk6. Int J Cancer 135: 1286-1296, 2014.

28. Gadducci A, Sergiampietri C, Lanfredini N and Guiggi I: Micro-RNAs and ovarian cancer: The state of art and perspectives of clinical research. Gynecol Endocrinol 30: 266-271, 2014. 
29. Salem M, Shan Y, Bernaudo S and Peng C: miR-590-3p targets cyclin G2 and FOXO3 to promote ovarian cancer cell proliferation, invasion, and spheroid formation. Int J Mol Sci 20: E1810, 2019

30. Zhou J,Zhang C,Zhou B and Jiang D: miR-183 modulated cell proliferation and apoptosis in ovarian cancer through the TGF- $\beta / \mathrm{Smad} 4$ signaling pathway. Int J Mol Med 43: 1734-1746, 2019.

31. Kanitz A, Imig J, Dziunycz PJ, Primorac A, Galgano A, Hofbauer GF, Gerber AP and Detmar M: The expression levels of MicroRNA-361-5p and its target VEGFA are inversely correlated in human cutaneous squamous cell carcinoma. PLoS One 7: e49568, 2012.

32. Liu D, Tao T, Xu B, Chen S, Liu C, Zhang L, Lu K, Huang Y, Jiang L, Zhang X, et al: MiR-361-5p acts as a tumor suppressor in prostate cancer by targeting signal transducer and activator of transcription-6 (STAT6). Biochem Biophys Res Commun 445: 151-156, 2014.

33. Häcker H, Redecke V, Blagoev B, Kratchmarova I, Hsu LC, Wang GG, Kamps MP, Raz E, Wagner H, Häcker G, et al: Specificity in Toll-like receptor signalling through distinct effector functions of TRAF3 and TRAF6. Nature 439: 204-207, 2006.
34. Oganesyan G, Saha SK, Guo B,He JQ, Shahangian A, Zarnegar B, Perry A and Cheng G: Critical role of TRAF3 in the Toll-like receptor-dependent and -independent antiviral response. Nature 439: 208-211, 2006.

35. Xie P: TRAF molecules in cell signaling and in human diseases. J Mol Signal 8: 7, 2013.

36. Rehei AL, Zhang L, Fu YX, Mu WB, Yang DS, Liu Y, Zhou SJ and Younusi A: MicroRNA-214 functions as an oncogene in human osteosarcoma by targeting TRAF3. Eur Rev Med Pharmacol Sci 22: 5156-5164, 2018.

(i) (9) This work is licensed under a Creative Commons

caY No No Attribution-NonCommercial-NoDerivatives 4.0 International (CC BY-NC-ND 4.0) License. 